\title{
ENVIRONMENTAL CHARACTERISTICS OF OLDER PEOPLE ATTENDING PHYSICAL MEDICINE AND REHABILITATION OUTPATIENT CLINICS
}

\author{
Mehmet Beyazova', Asuman Doğan², Yeşim Gökçe Kutsal ${ }^{3}$, Sevilay Karahann', Şule Arslan ${ }^{5}$, Kutay Ordu Gökkaya², \\ Füsun Toraman ${ }^{6}$, Nilay Dinçer ${ }^{7}$, Sami Hizmetli ${ }^{8}$, Kazım Şenel ${ }^{9}$, Pelin Yazgan ${ }^{10}$, Özgür Ortancıl ${ }^{11}$, Jale İrdesel ${ }^{12}$, \\ Özden Özyemişçi-Taşkıran ${ }^{13}$, Pınar Borman ${ }^{3}$, Müesser Okumuş ${ }^{14}$, Esma Ceceli ${ }^{14}$, Deniz Evcik ${ }^{15}$, Saime Ay ${ }^{15}$, Pınar \\ Öztop ${ }^{16}$, Nur Turhan ${ }^{17}$, Nurten Eskiyurt ${ }^{18}$, Rezzan Günaydın ${ }^{19}$, Sibel Eyigör ${ }^{20}$, Özlem Altındağ ${ }^{21}$, Ali Aydeniz ${ }^{21}$
}

${ }^{1}$ Darüşşafaka Physical Medicine and Rehabilitation Centre, Istanbul, Turkey

2Department of Physical Medicine and Rehabilitation, Ankara PMR Education and Research Hospital, Ankara, Turkey

${ }^{3}$ Department of Physical Medicine and Rehabilitation, School of Medicine, Hacettepe University, Ankara, Turkey

${ }^{4}$ Department of Statistics, Faculty of Medicine, Hacettepe University, Ankara, Turkey

${ }^{5}$ Department of Physical Medicine and Rehabilitation, Acibadem Atakent Hospital, Istanbul, Turkey

${ }^{6}$ Department of Physical Medicine and Rehabilitation, Antalya Atatürk Education and Research Hospital, Antalya, Turkey

${ }^{7}$ Department of Physical Medicine and Rehabilitation, Meram Medical School, Necmettin Erbakan University, Konya, Turkey

${ }^{8}$ Department of Physical Medicine and Rehabilitation, School of Medicine, Cumhuriyet University, Sivas, Turkey

${ }^{9}$ Department of Physical Medicine and Rehabilitation, Medical Faculty, Atatürk University, Erzurum, Turkey

${ }^{10}$ Department of Physical Medicine and Rehabilitation, Faculty of Medicine, Harran University, Sanliurfa, Turkey

${ }^{11}$ Department of Physical Medicine and Rehabilitation, Faculty of Medicine, Zonguldak Bülent Ecevit University, Zonguldak, Turkey

${ }^{12}$ Department of Physical Medicine and Rehabilitation, Faculty of Medicine, Uludağ University, Bursa, Turkey

${ }^{13}$ Department of Physical Medicine and Rehabilitation, Gazi University, Ankara, Turkey

${ }^{14}$ Department of Physical Medicine and Rehabilitation, Ankara Education and Research Hospital, Ministry of Health, Ankara, Turkey

${ }^{15}$ Department of Physical Medicine and Rehabilitation, Faculty of Medicine, Ufuk University, Ankara, Turkey

${ }^{16}$ Department of Physical Medicine and Rehabilitation, School of Medicine, Baskent University, Istanbul, Turkey

${ }^{17}$ Department of Physical Medicine and Rehabilitation, Bayındır Hospital, Icerenköy Istanbul, Turkey

${ }^{18}$ Department of Physical Medicine and Rehabilitation, School of Medicine, Istanbul University, Istanbul, Turkey

${ }^{19}$ Department of Physical Medicine and Rehabilitation, Izmir Training and Research Hospital, Izmir, Turkey

${ }^{20}$ Department of Physical Medicine and Rehabilitation, Faculty of Medicine, Ege University, Izmir, Turkey

${ }^{21}$ Department of Physical Medicine and Rehabilitation, Faculty of Medicine, Gaziantep University, Gaziantep, Turkey

\section{SUMMARY}

Objective: A residential environment refers to the physical and social characteristics in a neighbourhood. The physical characteristics include interior housing qualities, exterior neighbourhood characteristics, and the accessibility of essential facilities and services outside the neighbourhood. Older adults especially may be vulnerable to the negative impacts of the residential environment. The aim of this study is to elucidate the problems ageing people face in their neighbourhoods, buildings and public areas.

Methods: The study group consisted of a total of 1,001 people over the age of 65 who were admitted to physical medicine and rehabilitation clinics in Turkey and consented to participate. A questionnaire covering demographic, social and environmental information was used.

Results: Of the study group, $58.6 \%$ was living in an apartment building, but only $23.6 \%$ of these buildings had an elevator, and the stairs were inconvenient in $46.7 \%$ of the buildings. Only $49 \%$ of the elderly people went for a walk regularly. The most frequent complaint about the hospitals, community health centres and other public areas was the inappropriate restroom conditions. Eighty-six percent of the study group were not members of an organization, a foundation or a group, and $73.6 \%$ did not have personal hobbies.

Conclusions: The layouts of buildings and surroundings are inappropriate for older people, and the opportunities for them to participate in social activities are limited. Health and social programmes and governmental and local policies for older people are needed, and public awareness about this issue should be raised.

Key words: environment, social life, aged population

Address for correspondence: M. Beyazova, Darüşşafaka Physical Medicine and Rehabilitation Centre, Zümrütevler Mah. Mercan Sok. 37, Maltepe, Istanbul, Turkey. E-mail: mehmet.beyazova@gmail.com

https://doi.org/10.21101/cejph.a5194 


\section{INTRODUCTION}

Environmental conditions, described as the social and physical circumstances in which a person lives, influence their participation (1). An individual's environmental conditions include his or her social environment, such as friends and family, available government and public services, and physical environment, such as accessible buildings, home environment, pavements, roads, traffic, and weather. Studies have focused mainly on the effects of barriers or facilitators at home, but the outdoor environment may also significantly affect an individual's independence. Older people may be affected by the inaccessibility and difficulties presented by many outdoor environments. An age-friendly environment is a multifaceted concept that includes the physical and social infrastructure $(2,3)$. Since an adaptive environment may help elderly people age in their home environment, developing age-friendly environments is becoming a focus of social policy in many countries (4).

Mobility barriers are present in the community (5), and environmental barriers and facilitators can also influence participation in a general rehabilitation cohort (6). The gap between an individual's capacity and actual performance in daily activities may be explained by environmental factors (7). A systematic review studying the effects of the neighbourhood environment on the health of older individuals suggests that the neighbourhood environment affects health outcomes, such as mortality, morbidity, self-reported health or quality of life, mental health, cognition, disability, and physical activity (8). In a study that aimed to identify environmental barriers and investigate accessibility problems in the ordinary housing stock in Sweden, Granbom et al. showed that despite the high housing standards in Sweden, there is a high prevalence of environmental barriers and substantial accessibility problems for senior citizens with functional limitations (9). The median number of environmental barriers present was 31 (of 60) in multi-dwelling blocks and 32 in one-family houses.

Previous research studies have focused mainly on particular kinds of residential environments, health conditions, activities, perceptions, and socio-demographic factors. Person-environment relationships may be region-specific, as environmental factors vary between countries $(10,11)$. In this study, we aimed to elucidate the problems ageing people face in their neighbourhoods, buildings, and public areas.

\section{MATERIALS AND METHODS}

This multicentre study was carried out with patients aged 65 years and older who were admitted to physical medicine and rehabilitation (PMR) clinics between 1 September 2010 and 31 December 2010 (in 11 provinces and 23 centres) and agreed to participate in the survey. The patients were surveyed by the order of application. The physicians collected data on the socioeconomic and demographic characteristics in face-to-face interviews. An individual's educational status was recorded to be one of six categories: illiterate, literate, graduated from primary school (5 years), graduated from secondary school (3 years), graduated from high school or graduated from college/junior college. An individual's work status was recorded as one of the following: employed, retired, a farmer or a homemaker (engaged in household duties).
The questions used in the final instrument were based on the following age-friendly city topics: housing, transportation, outdoor spaces and buildings, social participation, community support and health services, respect and social inclusion, civic participation and employment, communication and information (12). The items of the questionnaire were based on the problems reported in the Global Age-friendly Cities Guide (12) and socioeconomic properties of the country and were discussed in the study group. This study was designed specifically to study these topics and was not included as part of another project. Data on the type of residence, environmental and residential barriers, transportation and utilization of healthcare facilities were also collected. The final instrument comprised 61 items, including items related to the specifications of the buildings, finances, transportation and time spent outside, mobility, physical environment, healthcare facilities, and social environment, and it could be completed in 20-30 minutes. All participants had sufficient time to complete the form.

The study was approved by the Ethical Committee of Ankara Training and Research Hospital (Approval No. 3451). There was no financial support for the study. The data were analysed using the Statistical Package for Social Sciences, version 15.0. The statistical significance level was set at $p<0.05$. For the descriptive statistics, the mean \pm standard deviation was used for the quantitative data, whereas numbers and percentages were used for qualitative data. Independent samples t test was used to compare males and females according to age. The chi-square test was used to compare the sex, income, and educational level between groups.

\section{RESULTS}

The study group consisted of 1,001 subjects (683 women, 318 men). The mean age was $69.9 \pm 6.5$ years for the women and $70.8 \pm 6.2$ years for the men $(p=0.047)$. Some of the demographic variables are shown in Table 1 , and the educational levels by sex are shown in Table 2. The subjects who lived with a spouse comprised $50.5 \%$ (498) of the study group, and $20.8 \%$ were living alone. Nursing home residents consisted of $0.4 \%$ of the study group, and subjects living with family members comprised $25.5 \%$. Regarding housing, 580 (58.6\%) of the subjects were living in flats, $285(28.8 \%)$ were living in private houses, $105(10.6 \%)$ were living in shanty houses, and $4(0.4 \%)$ were living in nursing homes. Of these buildings, $76.4 \%$ did not have elevators. A total of 176 subjects responded to the question about the suitability of the elevators and $19(10.8 \%)$ rated the elevator in their building as not suitable for older people because of the narrow space, inadequate lighting, inappropriate locations of the buttons, or because they had difficulty reading the flat numbers and/or signs. The question regarding the suitability of the stairs was answered by 569 subjects. Due to the unavailability of handrails, the presence of an excessive number of and/or the presence of high and narrow steps between flats and inadequate lighting, 266 subjects (46.7\%) reported that the stairs were inappropriate. Other properties of the buildings are presented in Table 3.

In total $837(84.4 \%)$ participants spent most of their time at home, 66 (6.7\%) spent most of their time in the garden and only $31(3.1 \%)$ spent most of their time at work. The subjects who needed help to go outside composed $19.4 \%$ of the study group. A total of $66.0 \%$ of the subjects were using glasses, hearing aids 
Table 1. Demographic variables of study participants

\begin{tabular}{|c|c|c|c|}
\hline & & $\mathrm{n}$ & $\%$ \\
\hline \multirow{4}{*}{ Occupation } & Retired & 490 & 58.3 \\
\hline & Employee & 28 & 3.3 \\
\hline & Housewife & 315 & 37.5 \\
\hline & Farmer & 8 & 1.0 \\
\hline \multirow{5}{*}{$\begin{array}{l}\text { Social } \\
\text { security type }\end{array}$} & None & 27 & 2.8 \\
\hline & Insurance by social security institution & 865 & 88.4 \\
\hline & Green card $^{\mathrm{a}}$ & 47 & 4.8 \\
\hline & Private assurance & 6 & 0.6 \\
\hline & Others & 34 & 3.5 \\
\hline \multirow{8}{*}{ Income } & No regular income & 135 & 14.0 \\
\hline & Under 500 TL & 157 & 16.2 \\
\hline & $500-1,000$ TL & 467 & 48.3 \\
\hline & $1,000-2,000 \mathrm{TL}$ & 125 & 12.9 \\
\hline & Above $2,000 \mathrm{TL}$ & 52 & 5.4 \\
\hline & Elderly insurance & 22 & 2.3 \\
\hline & Disability Insurance & 3 & 0.3 \\
\hline & Others & 6 & 0.6 \\
\hline \multirow{5}{*}{$\begin{array}{l}\text { Type } \\
\text { of residence }\end{array}$} & Greater municipality & 480 & 48.1 \\
\hline & Province & 157 & 15.7 \\
\hline & District & 210 & 21.1 \\
\hline & Small town & 47 & 4.7 \\
\hline & Village & 103 & 10.3 \\
\hline
\end{tabular}

areen card covers the health care costs for those living below the state determined poverty line.

TL - Turkish Lira

Table 2. Educational level of participants by sex

\begin{tabular}{|l|c|c|c|c|}
\hline \multirow{2}{*}{} & \multicolumn{2}{|c|}{ Women } & \multicolumn{2}{c|}{ Men } \\
\cline { 2 - 5 } & $\mathbf{n}$ & $\%$ & $\mathbf{n}$ & $\%$ \\
\hline Illiterate & 237 & 35.0 & 25 & 7.9 \\
\hline Literate & 91 & 13.4 & 23 & 7.3 \\
\hline Primary school (5 years) & 210 & 31.0 & 126 & 39.7 \\
\hline Secondary school (3 years) & 49 & 7.2 & 37 & 11.7 \\
\hline High school & 55 & 8.1 & 49 & 15.4 \\
\hline College/junior college & 36 & 5.3 & 57 & 18.0 \\
\hline
\end{tabular}

or other devices. Assistive devices/supports were used by 287 $(31.0 \%)$ subjects.

Of the subjects, $42.1 \%$ preferred to perform activities such as shopping, paying bills or banking by themselves, and $33.9 \%$ asked someone else for help. Only $4 \%$ of the participants used online banking or regular payment orders. The people who never went shopping comprised $20.1 \%$ of the study group. The question "how many times do you go out in a week" revealed that 42 $(4.3 \%)$ of them never went outside of their homes. Most of the elderly people (44.1\%) went out 1-2 times a week. The reasons for going outside of the home included to take a walk (49.0\%), shop $(37.0 \%)$, attend hospital (31.4\%), pay bills (14.3\%), participate in sportive activities (3.2\%), and perform other tasks (12.2\%). The lack of participation in community activities was caused by a fear of falling, air pollution, crowded streets, inadequate walking areas or parks, safety or health issues, such as musculoskeletal problems (39\%), cardiovascular diseases, and advanced hearing loss.

In total $759(78.5 \%)$ subjects could not go out at night because of inadequate lighting (7.0\%), difficulty in taking transportation $(5.5 \%)$, a fear of falling $(21.5 \%)$, and safety problems $(18.2 \%)$. Bad weather conditions were another factor affecting community participation; $27.4 \%$ of the study population stated that they never go out during bad weather conditions, and $63.7 \%$ stated they would not go out unless necessary since the sidewalks become slippery, curbstones become loose, transportation becomes difficult, and they have a fear of falling.

The community mobility barriers and transportation facilitators are provided in Table 4. Forty-eight percent of the respondents found the pavements in the neighbourhood inappropriate because of the high curbs (48.8\%); uneven (26.4\%), narrow $(24.3 \%)$, crowded $(13.0 \%)$ or slippery $(10.6 \%)$ pavements; pavements occupied by vehicles $(31.3 \%)$; and lack of ramps at the curbside (14.7\%). Only $13.4 \%$ of the study subjects were members of a group or a social club. In total $234(26.2 \%)$ reported that they enjoyed a regular activity, such as walking $(20.1 \%)$, gardening $(8.5 \%)$, handcrafts $(2.1 \%)$, knitting $(10.3 \%)$, participating in music/choral groups $(2.6 \%)$, reading books/crossword puzzles (13.2\%), chores (3.8\%) and meeting with friends (11.5\%); $20.7 \%$ of the participants had access to recreational facilities or reading areas where they lived.

In case of an emergency, $7.1 \%$ did not know what to do. Subjects who would call a relative or ask for the help of the neighbours composed $70.8 \%$ of the study population. Only $26.2 \%$ reported that they would call the police or emergency call centre. However, $392(41.4 \%)$ did not know the phone numbers of the police, fire department or the emergency call centre. Only $11 \%$ of the subjects knew all these phone numbers.

Regarding the correlation between the educational levels of the elderly people and the conditions of their residences and the physical and social environments, the findings of the study suggest that the conditions of the residences are better, the time spent at home is shorter, the rate of going out without company and the rate of performing regular outdoor activities such as shopping or bank transactions increase as the educational level increases $(p<0.001)$. The availability of green spaces and the rates of easy access to public spheres, having hobbies, and going out at night are statistically significantly higher when the education level is higher and socioeconomic conditions are better $(\mathrm{p}<0.001)$. Additionally, the rates of membership to a group, enjoying regular activities, spending time with friends, and using the nearby social facilities were higher in the group with a higher level of education $(\mathrm{p}<0.001)$.

The rate of women living alone was higher than that of men ( $27.2 \%$ vs. $7.0 \%$ ). The rate of spending most of the time at home was higher among women than among men, whereas the rates of participating in outdoor activities and membership in any association or group were higher among men.

Regarding the correlations between age and some other variables, the individuals with a lower educational level were older; those who performed outdoor activities by themselves, were able to go outdoors without company, went outdoors every day, and did not use any support on average were younger. The rate of spending 
Table 3. Properties of buildings

\begin{tabular}{|c|c|c|c|c|}
\hline & & $\mathrm{n}$ & $\%$ & Total number of respondents \\
\hline \multirow{5}{*}{ Floor } & Appropriate & 789 & 87.3 & \multirow{2}{*}{904} \\
\hline & Inappropriate & 115 & 12.7 & \\
\hline & Slippery surfaces & 25 & 21.7 & \\
\hline & Uneven surfaces & 51 & 44.3 & \\
\hline & Furniture blocking the way & 17 & 14.8 & \\
\hline \multirow{9}{*}{ Hallway } & Absent & 4 & 0.5 & \multirow{2}{*}{882} \\
\hline & Present & 878 & 99.5 & \\
\hline & Appropriate & 722 & 82.2 & \multirow{2}{*}{878} \\
\hline & Inappropriate & 156 & 17.8 & \\
\hline & Narrow & 77 & 49.4 & \\
\hline & Slopped & 16 & 10.3 & \\
\hline & Inadequate lighting & 26 & 16.7 & \\
\hline & No handrails & 34 & 21.8 & \\
\hline & Furniture blocking the way & 3 & 1.9 & \\
\hline \multirow{2}{*}{ Door handles } & Inappropriate & 63 & 7.0 & \multirow{2}{*}{899} \\
\hline & Appropriate & 836 & 93.0 & \\
\hline \multirow{2}{*}{ Doorsills } & Absent & 310 & 35.5 & \multirow{2}{*}{874} \\
\hline & Present & 564 & 64.5 & \\
\hline
\end{tabular}

Table 4. Community mobility barriers and transportation facilitators reported by the study group

\begin{tabular}{|c|c|c|c|}
\hline & $\mathrm{n}$ & $\%$ & Total number of respondents \\
\hline \multicolumn{4}{|l|}{ Community mobility barriers } \\
\hline Inappropriate pavements or other walking areas & 416 & 48.8 & 852 \\
\hline No parks in the neighborhood & 274 & 30.9 & 887 \\
\hline No walking areas for pedestrians & 122 & 21.3 & 573 \\
\hline Places to sit and rest & 140 & 23.9 & 586 \\
\hline Not enough traffic lights to cross the road & 309 & 37.5 & 824 \\
\hline Not enough time to cross the road at traffic lights & 266 & 40.7 & 654 \\
\hline \multicolumn{4}{|l|}{ Transportation facilitators } \\
\hline Reserved parking areas & 87 & 15.2 & 572 \\
\hline Easy access to shopping centres, hospitals, banks and official buildings & 656 & 74.8 & 877 \\
\hline Reduced fee or free transportation & 343 & 39.5 & 868 \\
\hline Places reserved for the elderly & 259 & 34.6 & 749 \\
\hline Lifts, ramps, moving stairways available & 345 & 54.9 & 628 \\
\hline Appropriate public transportation vehicles & 407 & 47.7 & 853 \\
\hline
\end{tabular}

time and entertaining with friends was significantly higher among the younger group $(\mathrm{p}<0.01)$. Although $76.6 \%$ of the participants were respected by the family and society, the approach of society towards older people was interpreted as unfavourable by $33.8 \%$ of the study group.

\section{DISCUSSION}

Previous empirical research studies suggest that many residential environmental, behavioural, perceptual and individual factors can affect older adults' health. Older adults' health is especially vulnerable to the negative impacts of residential environments (13). We aimed to evaluate the environmental factors that may affect ageing people. Most of the participants were living in flats or private houses and spent their time at home. Because of inadequate lighting, difficulty in transportation, a fear of falling and safety problems, the elderly people could not go out at night. Bad weather conditions were another factor affecting community participation. Most of the buildings did not have elevators. The stairs were considered inappropriate due to the unavailability of handrails, the presence of an excessive number of and/or the presence of high and narrow steps between flats, and inadequate lighting. In our study, most of the elderly people had a low income. 
While $33.4 \%$ of the study group did not have a fixed income or had to live on an income below minimum wage, $48.3 \%$ of the group had a low-middle income. The income levels in the environments of the participants have not been studied; however, it is already known that people with similar income levels live in similar environments in Turkey.

The immediate home environment is likely an important factor related to the neighbourhood that should be more closely examined regarding its physical environmental and social aspects that support active ageing (14). Good quality homes and neighbourhoods and a safe social environment contribute to better subjective, physical and mental health conditions of older adults (15). The rate of spending time at home was found to be high in our study, especially among women and older people (84.4\%). Most of the older people $(44.1 \%)$ went out 1-2 times a week, $78.5 \%$ of the subjects could not go out at night, and $27.4 \%$ of the study population stated that they never go out in bad weather conditions. A previous study that aimed to identify the prevalence of community mobility barriers and transportation facilitators revealed that approximately one-third of the subjects older than 65 years lived in a community with high mobility barriers and low transportation facilitators (16). The most frequently reported community barriers included "uneven sidewalks or walking areas," "no places to sit or rest," and "no curbs with curb cuts". High mobility barriers were associated with higher odds of daily activity limitations, and high transportation facilitators were associated with lower odds of daily activity limitations but not with the daily activity frequency in the adjusted models. Neighbourhoods with poor street structures were associated with decreased community ambulation, but this result was evident only among older people with functional limitations, thereby suggesting that the environment was limiting for persons with mobility limitations (17). Balfour and Kaplan assessed neighbourhood problems using a self-reported questionnaire (18). Subjects who reported more barriers in their neighbourhood were more likely to experience the onset of severe self-reported functional limitations over the course of one year. In our study, the lack of community participation was caused by air pollution, crowded and noisy streets, inadequate walking areas or parks, and safety problems. Neighbourhood physical environmental features, characteristics and amenities, such as safety and supportive features (e.g., well-maintained pedestrian infrastructure, adequate benches, street lights), low traffic volume and flow, adequate public transportation (e.g., transit routes, physical design of bus stops), and enjoyable scenery can play a role in supporting the mobility of older residents in their neighbourhoods $(19,20)$.

Regarding the direct impact of a residential environment, the housing quality has relatively strong positive associations with physical and mental health (15). Elderly people with better access to cultural facilities (including culture centres, universities for seniors and libraries) appear to have better mental health. The social aspects of the residential environment also significantly influence older people's health (15). The residential environment's impact on mental health and subjective overall health are enhanced by the individual's physical health. The residential environment affects the frequency in which older adults participate in physical and social activities thereby influences their health indirectly.

In a cohort study, Keysor et al. evaluated the impact of home and community environmental barriers and facilitators on participation after discharge from an acute care or inpatient reha- bilitation hospital (6). The subjects reported on average 3 home barriers and fewer than 1 barrier in the community. Most of the study participants lived in single-family homes or apartments or condominiums. Uneven sidewalks or other walking areas were reported by approximately $75 \%$ of the subjects. On average four mobility technology facilitators were reported; walkers, canes, commode adaptations, and shower adaptations were the most frequently used mobility technologies. In our study, in addition to environmental barriers, the physical conditions of the residences had many inappropriate elements (64\% of the doorsills and $46.7 \%$ of the stairs were inappropriate).

An advanced age, female sex, low socioeconomic conditions and lifestyles, limited social communication networks, inappropriate conditions at home, and a lack of social activities for the corresponding age group are among the most significant personal and environmental factors that decrease mobility among older subjects (21). Our study also suggests that individuals with low socioeconomic conditions and an advanced age are disadvantaged with respect to both physical and sociocultural conditions. Access to recreational facilities may influence physical activity participation. In a study, designed to evaluate the associations between access to recreational facilities and participation in recreational physical activity by socioeconomic status, it was found that the quality of the walking environment might be more important than the socioeconomic status of the area of residence as a correlate of walking (22).

Having green spaces is one of the most commonly mentioned age-friendly features. However, in many cities, there are barriers that prevent older people from using green spaces (12). In our study, $30.9 \%$ of the participants reported that there were no green spaces in their neighbourhood. In some parks, there were no walking areas for pedestrians or no places to sit and rest. The condition of the pavements has an obvious impact on the ability of individuals to walk in the surrounding area. Pavements that are narrow, uneven, cracked, have high curbs, are congested or have obstructions present potential hazards and affect the ability of older people to walk nearby. A total of $48.8 \%$ of our study population complained of inappropriate pavements or other walking areas in the neighbourhood.

Our study suggests that the social environment is as insufficient as the physical environment. The rates of membership to a club, having hobbies, and even meeting peer groups were considerably low. However, although the participants stated that the number of social facilities for the older people was low in their neighbourhood, the rate of those who said they would not be able to use them even if they had such facilities was also very high (44.5\%). Age and educational level in particular are important factors that have a strong correlation with the social environment and physical activities. In our study, the rate of university and higher education graduates was higher among the younger age group than among the older age group. People with higher educational levels also had higher income levels, and the conditions of their dwellings and neighbourhoods were better; the rate of time spent at home was lower, and the rate of performing outdoor activities independently, the rate of going out without company, and the rate of benefiting from the social environment and social facilities were higher. In a prospective population-based study, Droomers et al. evaluated the educational differences in individuals exhibiting decreased physical activity during leisure time among an adult, physically 
active population (23). They also defined predictors of these differences to be individual and environmental factors, which included life events, long lasting difficulties, equivalent income, the occurrence of financial problems, situational difficulties, and housing and neighbourhood circumstances. The respondents with a lower level of education experienced significantly higher odds of decreased physical activity during the follow-up compared with respondents with a higher level of vocational schooling or a university degree. In subjects older than 45 years, the educational differences in decreased physical activity were predicted by low perceived control in the groups with a lower educational level. Furthermore, less than good perceived health, financial problems and detrimental housing conditions contributed to educational differences in decreased physical activity.

An observational prospective cohort study showed that a fear of moving outdoors is common in older adults and increases the risk of developing self-reported difficulties in walking $0.5 \mathrm{~km}$ and 2 $\mathrm{km}$ (24). Being female, having a lower level of education, having musculoskeletal diseases, and the presence of noisy traffic correlated with a fear of moving outdoors. When subjects who reported difficulties walking $2 \mathrm{~km}$ at baseline were considered, it was observed that poor street conditions, noisy traffic, and hills increased the probability of having a fear of going outdoors. Furthermore, a higher socioeconomic status, indicated by a higher level of education and a good perceived financial situation, decreased the probability of a fear of going outdoors. The participants were not directly asked questions about a fear of going outdoors. However, their main reasons for not going outdoors included inappropriate environmental conditions, health problems, and a fear of falling. We also found a correlation between staying at home and being a woman, being older and having a lower level of education.

In a cross-sectional survey, it was found that subjects' participation in daily activities and social roles did not differ according to whether they lived in a metropolitan, urban or rural environment (25). However, subjects living in a metropolitan region differed, as they used a car less, were less satisfied with their social support and felt less secure in their neighbourhood than those living in an urban or rural environment. Another study suggested that individuals living in urban areas have access to more physical activities than those living in rural areas and that the physical environment is a significant moderator between physical activities and certain psychosocial factors (26). In our study, we did not compare the levels of physical activity between individuals living in urban and rural areas; however, the results of our study suggest that those living in urban areas have easier access to green spaces and public spheres and that the rates of their membership to associations and use of social facilities were statistically higher than of those individuals living in rural areas. Although sociodemographic and psychosocial factors are significant for physical activity, physical factors are far more significant $(27,28)$.

In most cities, the volume and speed of road traffic present barriers for older people, both as pedestrians and as drivers (12). Our study demonstrated that an insufficient number of crosswalks (51.1\%), short traffic lights, and drivers' reluctance to give way to pedestrians $(53.8 \%)$ are significant problems. In addition to age-friendly vehicles, seat priorities, and safe and comfortable transportation, respect to older drivers is also important (12). Our study suggests that most older people use public transportation $(42 \%)$ and benefit from discounted tickets for transportation
(39.5\%). However, while $34 \%$ of the study group stated that there were seats allocated to older people, $33 \%$ complained that they were not provided seats.

Inappropriate indoor and outdoor environmental factors significantly affect not only an individual's level of physical activity but also the fear of falling. As our study suggests, many factors, such as inappropriate building and dwelling entrances, inappropriate doorsills, lifts, stairs, and ramps, and insufficient lighting lead to falls or lead older people to stay at home (29).

The relations among the community, physical and social environments of aged patients who visited physical therapy centres with some other variables are described in this study. The principal limitation of this study is that the sample is limited to patients who were in sufficiently good health to visit physical therapy centres interdependently; subjects with severe comorbidities who were unable to leave their homes were excluded. The results of our study cannot be generalized to the society as a whole. We did not evaluate the cognitive functions of the participants, which may be another limitation of the study. Elderly patients who were seen in PMR clinics and could co-operate were included, and the patients had no difficulties with orientation according to the physical examination.

\section{CONCLUSION}

We found that even in urban areas, especially in environments where people with lower income and educational levels live, the building and environmental conditions are not appropriate for older people, and social facilities are insufficient. Older adults usually spend most of their time at home and do not go outside, even to deal with their own daily affairs. It is obvious that to ensure the independence of older people in their daily activities and to prevent their isolation from social activities, appropriate home and physical conditions and safe and sufficient social facilities are needed. Thus, the state and local authorities should make regulations for age-friendly physical and social environments, and the level of awareness should be raised on this topic. Continued interest is important to encourage professionals in order to improve environmental projects for seniors presented to the authorities.

\section{Conflict of Interests}

None declared

\section{REFERENCES}

1. World Health Organization. International classification of functioning, disability, and health: ICF. Geneva: WHO; 2001.

2. Plouffe L, Kalache A. Towards global age-friendly cities: determining urban features that promote active aging. J Urban Health. 2010;87(5):733-9.

3. Scharlach AE, Lehning AJ. Ageing-friendly communities and social inclusion in the United States of America. Ageing Soc. 2013;33(1):110-36.

4. Buffel T, Phillipson C. Ageing in urban environments: developing 'agefriendly' cities. Crit Soc Policy. 2012;32(4):597-617.

5. Whiteneck G, Meade MA, Dijkers M, Tate DG, Bushnik T, Forchheimer MB. Environmental factors and their role in participation and life satisfaction after spinal cord injury. Arch Phys Med Rehabil. 2004;85(11):1793803

6. Keysor JJ, Jette AM, Coster W, Bettger JP, Haley SM. Association of environmental factors with levels of home and community participation in an adult rehabilitation cohort. Arch Phys Med Rehabil. 2006;87(12):1566-75. 
7. Grimby G, Smedby B. ICF approved as the successor of ICIDH. J Rehabil Med. 2001;33(5):193-4.

8. Yen IH, Michael YL, Perdue L. Neighborhood environment in studies of health of older adults: a systematic review. Am J Prev Med. 2009;37(5):455-63.

9. Granbom M, Iwarsson S, Kylberg M, Pettersson C, Slaug B. A public health perspective to environmental barriers and accessibility problems for senior citizens living in ordinary housing. BMC Public Health. 2016;16:772. doi: 10.1186/s12889-016-3369-2.

10. Ding D, Adams MA, Sallis JF, Norman GJ, Hovell MF, Chambers CD, et al. Perceived neighborhood environment and physical activity in 11 countries: do associations differ by country? Int J Behav Nutr Phys Act. 2013;10:57. doi: 10.1186/1479-5868-10-57.

11. Adams MA, Frank LD, Schipperijn J, Smith G, Chapman J, Christiansen $\mathrm{LB}$, et al. International variation in neighborhood walkability, transit, and recreation environments using geographic information systems: the IPEN adult study. Int J Health Geogr. 2014;13:43. doi: 10.1186/1476-072X$13-43$.

12. World Health Organization. Global age-friendly cities: a guide. Ageing and life course, family and community health. Geneva: WHO; 2007.

13. Dujardin C, Lorant V, Thomas I. Self-assessed health of elderly people in Brussels: does the built environment matter? Health Place. 2014;27:59-67.

14. Chaudhury H, Campo M, Michael Y, Mahmood A. Neighbourhood environment and physical activity in older adults. Soc Sci Med. 2016;149:10411.

15. Liua Y, Dijsta M, Faberb J, Geertmana S, Cuic C. Healthy urban living: residential environment and health of older adults in Shanghai. Health Place. 2017;47:80-9.

16. Keysor JJ, Jette AM, LaValley MP, Lewis CE, Torner JC, Nevitt MC, et al.; The Multicenter Osteoarthritis (MOST) group. Community environmental factors are associated with disability in older adults with functional limitations: the MOST study. J Gerontol Biol Sci Med Sci. 2010;65(4):393-9.

17. Clarke P, Ailshire JA, Bader M, Morenoff JD, House JS. Mobility disability and the urban built environment. Am J Epidemiol. 2008;168(5):506-13.

18. Balfour JL, Kaplan GA. Neighborhood environment and loss of physical function in older adults: evidence from the Alameda County Study. Am J Epidemiol. 2002;155(6):507-15

19. Cauwenberg JV, Bourdeaudhuij ID, Meester FD, Dyck DV, Salmon J, Clarys P, et al. Relationship between the physical environment and physical activity in older adults: a systematic review. Health Place. 2011;17(2):458-69.

20. Rosso AL, Grubesic TH, Auchincloss AH, Tabb LP, Michael YL. Neighbourhood amenities and mobility in older adults. Am J Epidemiol. 2013;178(5):761-9.

21. Yeom HA, Fleury J, Keller C. Risk factors for mobility limitation in community-dwelling older adults: a social ecological perspective. Geriatr Nurs. 2008;29(2):133-40.

22. Giles-Corti B, Donovan RJ. Socioeconomic status differences in recreational physical activity levels and real and perceived access to a supportive physical environment. Prevent Med. 2002;35(6):601-11.

23. Droomers M, Schrijvers CTM, Mackenbach JP. Educational level and decreases in leisure time physical activity: predictors from the longitudinal GLOBE study. J Epidemiol Community Health. 2001;55(8):562-8.

24. Rantakokko M, Mänty M, Iwarsson S, Törmäkangas T, Leinonen R, Heikkinen E, et al. Fear of moving outdoors and development of outdoor walking difficulty in older people. J Am Geriatr Soc. 2009;57(4):634-40.

25. Therrien FH, Desrosiers J. Participation of metropolitan, urban and rural community-dwelling older adults. Arch Gerontol Geriatrics. 2010;51(3):52-6.

26. Dyck DV, Cardon G, Deforche B, De Bourdeaudhuij I. Urban-rura differences in physical activity in Belgian adults and the importance of psychosocial factors. J Urban Health. 2011;8(1):154-67.

27. Sigmundová D, El Ansari W, Sigmund E. Neighbourhood environment correlates of physical activity: a study of eight Czech regional towns. In J Environ Res Public Health. 2011;8(2):341-57.

28. De Greef K, Van Dyck D, Deforche B, De Bourdeaudhuij I. Physical environmental correlates of self-reported and objectively assessed physical activity in Belgian type 2 diabetes patients. Health Soc Care Community. 2011;19(2):178-88.

29. World Health Organization. Determinants of active ageing as they relate to falls in older age. In: WHO global report on falls prevention in older age. Geneva: WHO; 2008. p. 13-9.

Received August 29, 2017 Accepted in revised form January 30, 2020 